\title{
ECHOCARDIOGRAPHIC FINDINGS IN COPD AND THEIR CORRELATION TO SEVERITY OF DISEASE- AN OBSERVATIONAL STUDY FROM NORTH INDIA
}

\author{
Shri Krishna Gautam¹, Brijesh Kumar², Anand Kumar Singh ${ }^{3}$, Mainak Deb ${ }^{4}$ \\ ${ }_{1}^{1}$ Assistant Professor, Department of Medicine, GSVM Medical College, Kanpur, U. P. \\ ${ }^{2}$ Associate Professor, Department of Medicine, GSVM Medical College, Kanpur, U. P. \\ ${ }^{3}$ Lecturer, Department of Medicine, UPUMS, Saifai, Etawah, U. P. \\ 4Junior Resident, Department of Medicine, GSVM Medical College, Kanpur, U. P.
}

ABSTRACT
BACKGROUND
Cardiovascular disease accounts for much of mortality and morbidity in COPD, according to literature echocardiography provides a
rapid, non-invasive and accurate method to evaluate cardiac function. This study was undertaken to study the echo-cardiographic
findings in COPD patients and to assess their correlation to severity of COPD.

\section{MATERIALS \& METHODS}

50 patients who were fulfilling selection criterion were randomly selected for this prospective observational study. They underwent thorough history taking and physical examination, basic laboratory investigations, chest X ray, PFT, ECG and transthoracic echocardiography to look for PAH and cor-pulmonale.

\section{RESULTS}

In this study $84 \%$ of the patients were males and $16 \%$ were females. The mean age was $59.94( \pm 10.37)$ years, range 40 -85 years. Majority of the patients had history of tobacco exposure of at least $20-29$ pack years. $36 \%$ of the patients had clinical evidence of congestive cardiac failure. Maximum number of patients $(60 \%)$ had severe airflow obstruction at the time of presentation and only $4 \%$ had mild disease. Overall, $54 \%$ of the patients in this study had echocardiographic evidence of cor-pulmonale, $56 \%$ had pulmonary hypertension, $48 \%$ had right ventricular dilatation, $28 \%$ patients had right ventricular hypertrophy, $14 \%$ of the patients had features of RV failure while $8 \%$ patients had left ventricular systolic dysfunction. PAH was seen in $68 \%$, $43 \%$ and $25 \%$ in the severe, moderate and mild disease groups, respectively. In the severe group, $73.3 \%(22 / 30)$ of the patients had echo evidence of pulmonary hypertension, and $76.7 \%(23 / 30)$ had cor-pulmonale. Only in the severe group $23.3 \%$ of the patients had echo evidence of RV failure. Left ventricular systolic dysfunction was present in 4 patients (13.3\%), all had severe COPD.

\section{CONCLUSION}

All the echocardiographic findings had statistically significant correlation with severity except RV hypertrophy, inter ventricular wall motion abnormality, and left ventricular systolic dysfunction. The incidence of all the echocardiographic findings increased as the severity of the disease increased. The echo signs of RV dilatation, RV failure, pulmonary hypertension, cor-pulmonale and LVDD correlated significantly with the severity of the disease $(\mathrm{p}<0.05)$

\section{KEYWORDS}

Echocardiography, COPD.

HOW TO CITE THIS ARTICLE: Gautam SK, Kumar B, Singh AK, et al. Echocardiographic findings in COPD and their correlation to severity of disease- an observational study from North India. J. Evolution Med. Dent. Sci. 2018;7(06):801-806, D0I: $10.14260 /$ jemds/2018/182

\section{BACKGROUND}

COPD is a leading cause of death and disability worldwide. According to World Bank data, it is expected to be the 3rd and 5 th leading cause of mortality and morbidity, respectively, in 2020. COPD is associated with significant systemic effects among which cardiac manifestations are most common. Cardiovascular disease accounts for approximately $50 \%$ of all hospitalization and nearly one third of all deaths, if FEV1 is < $50 \%$ of predicted. In more advanced COPD cardiovascular disease account for $20 \%-25 \%$ of all deaths. ${ }^{1}$

'Financial or Other Competing Interest': None.

Submission 29-12-2017, Peer Review 22-01-2018,

Acceptance 29-01-2018, Published 05-02-2018.

Corresponding Author:

Dr. Brijesh Kumar,

H. N. 2-D Block, GSVM Medical College Campus,

Kanpur-208002, U. P.

E-mail: drbrijeshkumar74@gmail.com

DOI: $10.14260 /$ jemds $/ 2018 / 182$

COPD is now considered a multisystemic disease with secondary changes affecting the cardiovascular system most conspicuously. Echocardiography provides an easily available valid method to quantify these changes at the bedside.

\section{MATERIALS AND METHODS}

This prospective observational study was undertaken to study the echocardiographic changes in COPD patients with different grades of severity of the disease, as assessed clinically and through pulmonary function testing, with the aim to-

1. Study the echocardiographic findings in patients of COPD.

2. Find out the correlation between echocardiographic findings and severity of COPD.

50 randomly selected patients who were admitted with signs and symptoms suggestive of COPD, both male and female, in PG Institute of Medicine, GSVM Medical College, Kanpur over a period of one and half years (Dec. 2012 to July 
2014) were chosen after fulfilling selection criterion for this study.

\section{Inclusion Criteria}

1. Patients with history of cough with expectoration of at least 3 months duration in 2 consecutive years. Patients with history of breathlessness of long standing duration with or without cough.

2. Giving written consent.

\section{Exclusion Criteria}

1. Patients with other diagnosed or suggestive pulmonary pathology like bronchial asthma, bronchiectasis, tuberculosis, pneumoconiosis, restrictive lung disease like kyphoscoliosis etc.

2. Patients with Rheumatic, Congenital or acquired heart disease such as ischemic heart disease, cardiomyopathies and systemic hypertension $>140 / 90$ mm Hg.

Patients were investigated when their condition stabilized, before they were discharged, after obtaining informed consent. In history taking, patients were asked about the duration of symptoms like cough, breathlessness, amount, nature and diurnal variation of expectoration and severity of breathlessness to clinically categorize them into predominant chronic bronchitis and predominant emphysema.

Patients were also asked about history of pedal edema, distension of abdomen, puffiness of face, right hypochondriac pain, to know whether the patient had developed RV dysfunction. Patients were asked about history suggestive of other respiratory and cardiovascular diseases. General physical and systemic clinical examination especially relevant to respiratory and cardiovascular system was done. Particular attention was given to the presence or absence of cyanosis, clubbing of fingers and signs of right heart failure.

According to Pulmonary Function Test, severity of COPD was assessed according to British Thoracic Society guidelines as Mild: FEV1 $60-79 \%$ of predicted, Moderate: FEV1 $=40$ $59 \%$ of predicted, Severe: FEV1 $<40 \%$ of predicted.

A chest X -ray PA view was taken in all patient and were screened for evidence of chronic bronchitis, emphysema, cardiomegaly and evidence of pulmonary hypertension.

A 12 lead ECG was taken in all the patients under study and 'P Pulmonale', RVH, Low voltage complexes, Poor progression of ' $R$ ' waves, Incomplete RBBB. Arrhythmias were looked for.

\section{Echocardiography}

All patients were subjected to echocardiographic examination including 2-D and M-mode echocardiography to note the presence of pulmonary hypertension, right ventricular hypertrophy, right ventricular dilatation and right ventricular failure and left ventricular systolic or diastolic dysfunction.

\section{The following points were noted:}

1. Pulmonary artery diameter.

2. Evidence of pulmonary hypertension on M-mode examination of pulmonary valve.
- 'a' wave (Normal - $2.7 \mathrm{~mm}$ ) (low in pulmonary hypertension).

- $\quad$ EF slope (Normal - $36.9 \pm 25.4 \mathrm{~mm} / \mathrm{sec}$ ) (low in pulmonary hypertension).

- Midsystolic notch and flutter.

3. Right ventricular hypertrophy (RVH).

- Thickness of anterior wall and septum; if $>6 \mathrm{~mm}$ RVH is present ${ }^{34}$

4. Right ventricular diastolic dimension if $>25 \mathrm{~mm}, \mathrm{RV}$ is dilated 34.

5. Right atrial dilatation $(>3.6 \mathrm{~cm}) 39$.

6. Right ventricular failure.

- Tricuspid regurgitation.

- RV wall motion abnormality.

- Dilatation of inferior vena cava and hepatic veins.

The presence of right ventricular dilation, right ventricular hypertrophy or right ventricular failure was taken as evidence of cor-pulmonale.

\section{The following conclusion were drawn}

- Normal echo study

- Pulmonary hypertension

- Pulmonary hypertension with cor-pulmonale

Left ventricular function was also assessed by using the following parameters: $\mathrm{EF}$ (ejection fraction) $=$ measure of how much end-diastolic volume is ejected from $\mathrm{LV}$ with each contraction (56\%-78\%)

$\mathrm{E} / \mathrm{A}=$ diastolic filling of left ventricles usually classified initially on the basis of the peak mitral flow velocity of the early rapid filling wave (E), peak velocity of the late filling wave caused by atrial contraction (A). In normal subjects LV elastic recoil is vigorous because of normal myocardial relaxation, therefore more filling is completed during early diastolic, so left ventricular diastolic dysfunction (LVDD) is said to be present when E/A is $<1.3$ (age group 45-49 years), $<1.2$ (age group 50-59 years), $<1.0$ (age group 60-69 years), and $<0.8$ (age group $\geq 70$ years). ${ }^{2}$

\section{All Patients were also subjected to Other Routine Investigations like-}

1. Hb\%, Total WBC count, Differential count, ESR

2. Urine Albumin, Sugar, microscopy

3. Sputum for Acid Fast Bacilli and Gram stain

4. Random blood Sugar, blood Urea, serum Creatinine

5. Arterial Blood Gas examination.

\section{Statistical Methods}

Results were tabulated in Microsoft Office Excel 2007 worksheet and expressed in mean \pm standard deviation for continuously distributed variables and in absolute numbers and percentages for discrete variables. Data was analysed using percentages and Chi Squaretest and p-value was computed; $p$ value of less than 0.05 was considered significant. SPSS version 16 was used for statistical analysis. The results were graphically represented using Microsoft Office Excel 2007. 


\section{RESULTS}

In this study $84 \%(42)$ of the patients were males and $16 \%(8)$ were females. The mean age was $59.94( \pm 10.37)$ years, range 40-85 years. The maximum incidence of COPD in this study is among the age group 50-69 years i.e. in the 6th and 7 th decade (66\%).No patients were less than 40 years, only $4 \%$ of the patients were $\geq 80$ years of age.

The mean duration of symptoms was $5.71( \pm 4.98)$ years, range 2 to 20 years. Maximum number of patients (62\%) had symptoms of 1-5 years of duration, and patients in more than 10 years of symptoms were only $10 \%$. The mean duration of tobacco use was 23.2 pack years with a range of 5 to 45 pack years. Majority of the patients had history of tobacco exposure of at least 20-29 pack years. Patients with less than 10 pack years of exposure were only $2 \%$.

All patients in this study had history of breathlessness at presentation. $96 \%$ of the patients had cough with sputum at presentation. $38 \%$ of the patients presented with oedema. The most common sign at presentation is tachypnoea, 70\% followed by epigastric pulsation. $32 \%$ of the patients had loud P2 suggestive of pulmonary hypertension.

$36 \%$ of the patients had evidence of congestive cardiac failure like raised JVP, oedema, hepatomegaly. $30 \%$ of the patients had parasternal heave, the clinical evidence of right ventricular hypertrophy. $26 \%$ of the patients had cyanosis, clubbing or both which is evidence of a hypoxic state.

The mean FEV1 was $36.01( \pm 12.23) \%$ of predicted, range 17 to $60 \%$ of predicted. Maximum number of patients (60\%) had severe airflow obstruction at the time of presentation and only $4 \%$ had mild disease. Majority of the patients with severe disease (70\% i.e., $21 / 30$ patients) had history of greater than 20 pack years of tobacco exposure.

Most common ECG finding in patients of COPD was Right ventricular hypertrophy (52\%), followed by $\mathrm{P}$ Pulmonale (48\%). Only $2 \%$ patients of COPD had found to have arrhythmia which is multifocal atrial tachycardia (MAT).

$54 \%$ of the patients in this study had echocardiographic evidence of cor-pulmonale. $56 \%$ of the patients had echocardiographic evidence of pulmonary hypertension. $48 \%$ of the patients had right ventricular dilatation and 28\% patients had right ventricular hypertrophy. $14 \%$ of the patients had echocardiographic features of RV failure and $18 \%$ had evidence of interventricular septal motion abnormalities. $38 \%$ of the patients had right atrial dilatation. $32 \%$ patients had left ventricular dysfunction and $8 \%$ patients had left ventricular systolic dysfunction.

In the mild group only 1 patient had echo evidence of pulmonary hypertension and no patient had evidence of corpulmonale. In moderate group, $27.8 \%$ ( i.e. 5/18) of the patients had echocardiography evidence of pulmonary hypertension and $22.2 \%$ (i.e. $4 / 18$ ) had evidence of corpulmonale.

In the severe group, $73.3 \%(22 / 30)$ of the patients had echo evidence of pulmonary hypertension, and 76.7\%(23/30) had echocardiographic evidence of corpulmonale. Only in the severe group $23.3 \%(7 / 30)$ of the patients had echo evidence of RV failure. Left ventricular diastolic dysfunction was present in 16 (57.7\%) patients out of which 14 (46.6\%) patients had severe COPD while 2 (11.1\%) had moderate COPD. Left ventricular systolic dysfunction was present in 4 patients (13.3\%), all had severe COPD. The echo signs of RA dilatation, RV dilatation, RV failure, pulmonary. Hypertension, cor-pulmonale and LVDD correlated significantly with the severity of the disease $(\mathrm{p}<$ 0.05).

\section{DISCUSSION}

\section{Sex Distribution}

In this study the male: female ratio was 5.25:1.0, i.e. males form $84 \%(42 / 50)$ of the study subjects. This higher incidence of COPD in males can be attributed to smoking. In our study none of the females were smokers but all of them had history of cooking with dried cow dung or dried wood fuel. Males:Females ratio in other studies varied from 80\%(J.C.Banergae;19663) and 81.25(Chappell A.G.;1966,4) to 92\%(Benjamin Burrows;1972,5)94.6\%(V. K. Singh;1989.6)

\section{Age Distribution}

The maximum number of COPD patients (35/50) in this study was in the age group of 50-69 years with mean age $59.94 \pm$ 10.37 years, which is similar to previous studies $50.2 \pm 12$ yrs. (Gupta \& Khastgir, 19897),56.5 \pm 7.4 yrs. (Burrows, 19725),59 \pm 7 yrs. (Keller \&Shepard, 1986), 59.25 yrs. (Putnik \& Povazan, 19889),66 \pm 6 yrs. (Himelmann 198810). Patients between 50-70 yrs. form the maximum number of patients admitted, mainly because of the longer duration of tobacco exposure and repeated respiratory tract infections, which would have compromised their quality of life.

\section{Duration of Symptoms}

In this study most of the patients $(31 / 50)$ gave history of symptoms of 1-5 years duration, with a mean duration of dyspnoea and cough of 5.71 years. In the study conducted by Gupta et al, 19897, the mean duration of symptoms was $8.9 \pm 4.9$ years and in the study of J.C. Banergae ${ }^{3}$, the mean duration of cough was 5.4 yrs. and dyspnoea was 1.94 years.

\section{Severity of the disease}

In the present study, $60 \%(30 / 50)$ of the patients had FEV1 < $40 \%$ of the predicted i.e. severe obstructive disease. Patients with mild obstructive defect (4\% only), that is FEV1 60-79\% of predicted are usually in the pre-symptomatic stage and are not likely to come to medical attention.

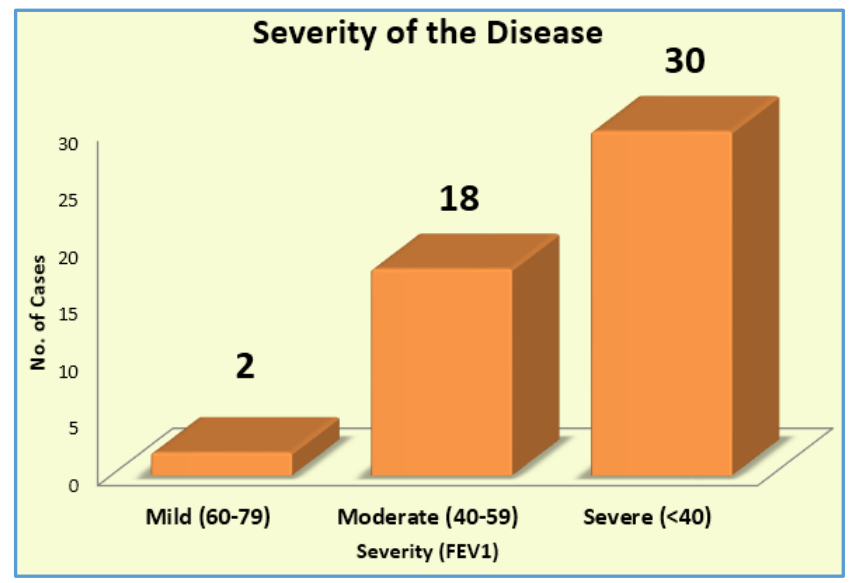


Comparison with other Studies

\begin{tabular}{|c|c|c|c|}
\hline FEV1 & $\begin{array}{c}\text { Gupta \& } \\
\text { Khastgir }^{7} \\
\text { (1989) n (\%) }\end{array}$ & $\begin{array}{c}\text { Higham et al, } \\
\mathbf{1 9 8 8} \text { n (\%) }\end{array}$ & $\begin{array}{c}\text { Present } \\
\text { n (\%) }\end{array}$ \\
\hline $60-79 \%$ Mild & $1(3.48 \%)$ & $12(16.4 \%)$ & $2(4 \%)$ \\
\hline $\begin{array}{c}40-59 \% \\
\text { Moderate }\end{array}$ & $5(17.2 \%)$ & $19(26 \%)$ & $18(36 \%)$ \\
\hline$<40 \%$ Severe & $23(79.3 \%)$ & $42(57.6 \%)$ & $30(60 \%)$ \\
\hline
\end{tabular}

So it is seen that the findings in this study correlate with the previous studies.

\section{Duration of tobacco use and correlation to severity of disease}

In this study, majority of the patients (30/50) had a history of tobacco use of atleast 20-29 pack-years, with a mean of 23.2 ( \pm 3.6 ) years. And according to BTS guide lines most patients with COPD have at least in 20 pack years of smoking history ${ }^{11}$. In the study by Gupta and Khastgir ${ }^{7}$ mean of 26.4 $( \pm 16.1$ ) pack years of smoking history was found, which is similar to the present study.

\section{Symptoms at presentation}

Breathlessness is the symptom that commonly causes the patient to seek medical attention, and is usually the most disabling of his symptoms. The increased number of patients with oedema and scanty urine in J.C. Banergea's study is because; all the patients in the study had cor-pulmonale.

\section{Physical signs at presentation}

Most of the patients in the present study had tachypnoea on presentation. Most of them had signs of hyperinflation, and also diminished breath sounds with prolonged expiratory phase. Clinical signs of right ventricular hypertrophy were present in $30 \%(15 / 50)$ of the patients and pulmonary hypertension in $32 \%(16 / 50)$ of the patients. The higher incidence of most of the signs of RVH and pulmonary hypertension and CHF in the study by Gupta and Khastgir ${ }^{7}$ can be explained by the fact that their study included nearly $80 \%$ of the patients with severe disease $(38 \%$ of the patients with FEV1 <20) \% of predicted signifying advanced disease and only $17 \%$ of patients with moderate disease (FEV1 40 59) $\%$ of predicted compared to $36 \%$ in the present study.

\section{ECG Findings}

\begin{tabular}{|c|c|c|c|c|}
\hline Author and Year & $\begin{array}{c}\text { RVH } \\
\text { (\%) }\end{array}$ & $\begin{array}{c}\text { P Pul- } \\
\text { monale } \\
\text { (\%) }\end{array}$ & $\begin{array}{c}\text { Low } \\
\text { Volt- } \\
\text { age } \\
\text { QRS } \\
\text { (\%) }\end{array}$ & $\begin{array}{c}\text { Poor Pro- } \\
\text { gression } \\
\text { of R (\%) }\end{array}$ \\
\hline Ralph C. Scotte;195512 & 53.5 & - & - & - \\
\hline $\begin{array}{c}\text { Phillips and } \\
\text { Providence; } 1958^{13}\end{array}$ & $38-72 *$ & - & - & - \\
\hline $\begin{array}{c}\text { Padmavathi\& } \\
\text { Pathak;195914 }\end{array}$ & 73 & - & - & - \\
\hline $\begin{array}{c}\text { Caird and Wilcken; } \\
\text { 1962 } 15\end{array}$ & 16 & 36.7 & - & - \\
\hline Fowler et al, 196316 & - & 33 & 40 & 27 \\
\hline $\begin{array}{c}\text { A. G. Chappel; } \\
\text { 1966 }\end{array}$ & 10 & 10 & - & - \\
\hline FJC Millard;196717 & 45.7 & - & - & - \\
\hline
\end{tabular}

\begin{tabular}{|c|c|c|c|c|}
\hline $\begin{array}{c}\text { Silver and Calatayud, } \\
1970^{18}\end{array}$ & - & 46.2 & 29 & - \\
\hline $\begin{array}{c}\text { Padmavathi \& } \\
\text { Raizada; } \\
1972^{19}\end{array}$ & 59.7 & 95 & 41 & 17.2 \\
\hline $\begin{array}{c}\text { Murphy and } \\
\text { Hutcheson; } \\
197420\end{array}$ & 43.66 & 26.4 & 58.5 & - \\
\hline $\begin{array}{c}\text { Gupta \& Khastgir; } \\
1989^{7}\end{array}$ & 50 & 43.3 & - & - \\
\hline Present Study & 44 & 48 & 28 & 32 \\
\hline
\end{tabular}

* using different criterion.

In this study $44 \%(22 / 50)$ of the patients had ECG evidence of RVH, with criteria used as given by Braunwald 21 . The incidence of RVH by ECG varies in different studies, depending on the number of patients in cor-pulmonale in the study, and the criteria used by the authors. From the above table, it is clear that the incidence of RVH varies widely in different studies. Our findings correlate with the findings of F.J.C. Millard (45.7\%) and Murphy and Hutcheson (43.66\%) and Gupta and Khastgir(50\%).

The findings of p-pulmonale in this study is similar to Gupta and Khastgir (43.3\%) ${ }^{7}$ and Silver Calatayud (46.2). ${ }^{18} \mathrm{P}-$ pulmonale has been used as an indirect evidence of right ventricular hypertrophy by various authors. (Winternitz, 1935; Hecht, 1937; Katz 1946; Wood 1948 etc.). Others regarded it as a positional changed due to hyperinflation, lowering of diaphragm and vertical position of the heart.19 Padmavathi and Raizada ${ }^{19}$ state that its occurrence must be attributed largely to positional and partly to hemodynamic changes, but it cannot be designated an unequivocal criterion of RVH.

The findings of low voltage QRS complexes in our study correlate with the study of Silver and Calatayud. Mark and Snider (1956) have ascribed this to an increased amount of air containing lung between heart and the chest wall, so that the direction of QRS vector becomes perpendicular to the frontal plane. This is described as evidence of emphysema. Poor progression of ' $R$ ' wave is also due to changes in the position of the heart due to pulmonary emphysema. In this study only one patient had transient multifocal atrial ectopic. In a study by Chappell 4 of 112 patients, one patient had atrial flutter, and another had paroxysmal atrial fibrillation.

9. Analysis of Echocardiographic findings: In the present study, $54 \%(27 / 50)$ of the patients had echocardiographic evidence of cor-pulmonale, comprising of RV dilatation, RV hypertrophy, RA dilatation or evidence of RV failure, or interventricular septum motion abnormality. Incidence of the individual findings in this study and comparing with a previous study is as follows.

\begin{tabular}{|c|c|c|}
\hline Echo finding & $\begin{array}{c}\text { Himelmann, } \\
\mathbf{1 9 5 8 1 0}^{(\%)}\end{array}$ & $\begin{array}{c}\text { Present study } \\
\text { (\%) }\end{array}$ \\
\hline R. V. dilatation & 55 & 48 \\
\hline R. A. enlargement & 39 & 38 \\
\hline R. V. hypertrophy & 25 & 28 \\
\hline $\begin{array}{c}\text { Pulmonary } \\
\text { hypertension }\end{array}$ & 49 & 56 \\
\hline Cor-pulmonale & 75 & 54 \\
\hline
\end{tabular}


From the above table, it is clear that the findings in our study correlates well with most of the findings in the study by Himelmann, except the higher incidence of cor-pulmonale in his study. This can be explained by the fact all patients in that study had severe airway obstruction.

Incidence of inter-ventricular septum motion abnormality: In the present study (9/50) patients (18\%) had echocardiographic evidence of inter-ventricular motion abnormality in the form of paradoxical movement or systolic bowing into the left ventricle, which is a sign of systolic over load of right ventricle. In a study by Danchin ${ }^{22}$ (1987) 3 patients $(7.5 \%)$ had paradoxical motion of the interventricular septum.

The classical view of the development of heart failure in patients with COPD is that hypoxia leads to pulmonary hypertension, which imposes, increased work on the right ventricle, leading to right ventricular hypertrophy and eventually $\mathrm{RV}$ dilatation and then $\mathrm{RV}$ failure. The RA dilatation is a consequence of systolic overload on RA due to RV hypertrophy. In present study left ventricular diastolic dysfunction is present in $57.7 \%$ patients, and left ventricular systolic dysfunction present in $13.3 \%$ in previous studies it was present in $4 \%-32 \%$ patients of COPD. 23,24

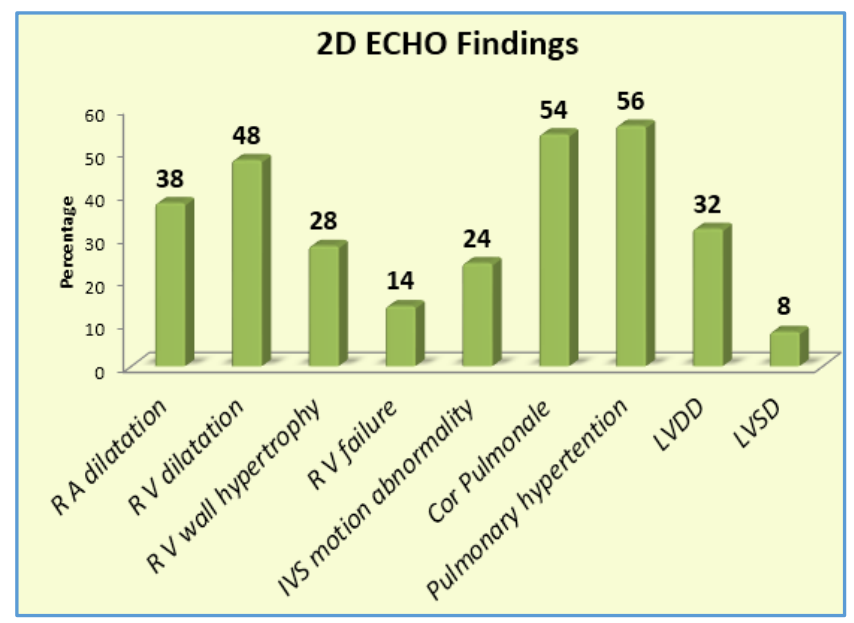

10. Correlation of echocardiographic findings with severity of the disease

In the present study, the incidence of all the echocardiographic findings increased as the severity of the disease increased, i.e. maximum incidence was found in the most severely affected group of patients.

\begin{tabular}{|c|c|c|c|c|c|c|c|c|}
\hline \multirow{2}{*}{ Echo Finding } & \multicolumn{2}{|c|}{ Mild } & \multicolumn{4}{|c|}{\begin{tabular}{|l|l|} 
Moderate & Severe \\
\end{tabular}} & \multirow{2}{*}{ ' $\mathrm{x}^{2}$ ' } & \multirow{2}{*}{ 'P' } \\
\hline & No & $\%$ & No & $\%$ & No & $\%$ & & \\
\hline R. A. dilatation & 1 & 50 & 3 & 16.7 & 15 & 50 & 4.584 & 0.032 \\
\hline R.V. dilatation & & & 2 & 11 & 22 & 73.3 & 19.284 & $<0.001$ \\
\hline $\begin{array}{c}\text { R.V. } \\
\text { hypertrophy }\end{array}$ & & & 3 & 16.7 & 11 & 36.7 & 2.794 & 0.095 \\
\hline R.V. failure & & & & & 7 & 23.3 & 5.426 & 0.020 \\
\hline $\begin{array}{l}\text { IVS motion } \\
\text { abnormality }\end{array}$ & & & 2 & 11.1 & 10 & 33.3 & 3.817 & 0.051 \\
\hline $\begin{array}{c}\text { Pulmonary } \\
\text { hypertension }\end{array}$ & 1 & 50 & 5 & 27.8 & 22 & 73.3 & 9.145 & 0.002 \\
\hline Cor-pulmonale & & & 4 & 22.2 & 23 & 76.7 & 15.513 & $<0.001$ \\
\hline LVDD & & & 2 & 11.1 & 14 & 46.6 & 7.41 & 0.006 \\
\hline LVSD & & & & & 4 & 13.3 & 2.90 & 0.089 \\
\hline
\end{tabular}

All the findings had statistically significant correlation with severity except RV hypertrophy and inter ventricular wall motion abnormality, and left ventricular systolic dysfunction. This is probably because of (1) lesser number of patients in the moderate severity group. (2) Relative difficulty in getting the exact measurement of the thickness of R.V. free wall, as it is difficult to differentiate from the surrounding structures and (3) Local variations in the right ventricular wall thickness in relation to the presence of trabeculae the right ventricle.

Comparing the findings in moderate and severe groups in this study: R.A. dilatation -- $16.7 \%$ Vs $50 \%$; R.V. dilatation -$11 \%$ Vs $73.3 \%$; R. V. Hypertrophy $-16 \%$ Vs $36.7 \%$; R. V. failure $-0 \%$ Vs $23.3 \%$; IVS motion abnormality $--5.6 \%$ Vs 26.7\%; Pulmonary hypertension --27.8\% Vs 73.3\%; Corpulmonale--22.2\% Vs 76\%; LVDD -- $11.1 \%$ Vs $46.6 \%$; LVSD -$0 \%$ Vs $13.3 \%$.

Danchin (1987)22 in his study compared echocardiographic parameters in COPD patients, with and without history of right heart failure, and found that patients who had no history of right heart failure had smaller right ventricular areas, that those with one or more episodes of right heart failure.

This implies that patients with history of right heart failure i.e. more severe disease is more likely to have right ventricular enlargement thus correlating with the finding in the present study.

Comparison of Pulmonary Hypertension.

\begin{tabular}{|c|c|c|}
\hline Severity & Higham et al, 200125 & Present study \\
\hline Mild & $(\mathrm{n}=12) \mathbf{2 5} \%$ & $(\mathrm{n}=2) \mathbf{5 0} \%$ \\
\hline Moderate & $(\mathrm{n}=19) \mathbf{4 3} \%$ & $(\mathrm{n}=18) \mathbf{2 8} \%$ \\
\hline Severe & $(\mathrm{n}=42) \mathbf{6 8} \%$ & $(\mathrm{n}=30) \mathbf{7 3} \%$ \\
\hline
\end{tabular}

The relatively high incidence of pulmonary hypertension is the mild group in the present study is possibly because, there were only 2 patients in the mild group compared to 12 patients in study by Higham et al. But the incidence in the moderate and the severe groups are found to be fairly correlating.

In present study left ventricular diastolic dysfunction was present in 16 (57.7\%) patients out of which 14 (46.6\%) patients had severe COPD while $2(11.1 \%)$ had moderate COPD which is statistically significant (p value- 0.006 ). Left ventricular systolic dysfunction was present in 4 patients (13.3), all had severe COPD. Which is statistically not significant ( $\mathrm{p}$ value- 0.089 ).

\section{CONCLUSION}

Echocardiographic evidence of cor-pulmonale was found in $54 \%$ of patients, pulmonary hypertension in $56 \%$. Statistically significant correlation with severity was found in the incidence of RA and RV dilatation, RV failure, corpulmonale and LVDD among echo finding ( $P$ value $<0.05$ ).

Our study found a positive correlation between the severity of disease and cardiovascular complications and an overall considerable prevalence of such complications in COPD patients. Such complications have additional treatment implications, making echocardiographic screening of COPD patients necessary and useful. 


\section{REFERENCES}

[1] Sin DD, Anthonisen NR, Soriano JB, et al. Mortality in COPD: role of comorbidities. Eur Respir J 2006;28(6):1245-57.

[2] Libby P, Bonow RO, Zipes DP, et al. Braunwald's Heart disease. $8^{\text {th }}$ edn. Philadelphia: Saunders 2008; p. 251.

[3] Banerjea JC. Natural history and sympotomatology of chronic cor pulmonale. Indian Journal Chest Disease 1965;7(4):174-81.

[4] Chappel AG. The electrocardiogram in chronic bronchitis and emphysema. Bri Heart J 1966;28(4):517-22.

[5] Burrows B, Kettel LJ, Niden AH, et al. Patterns of cardiovascular dysufunction in chronic obstructive lung disease. N Engl J Med 1972;286(17):912-8.

[6] Singh VK, Jain SK. Effects of airflow limitation on the electrocardiogram in COPD. Indian Journal of chest diseases and Allied Sciences 1989;31(1):1-8.

[7] Gupta S, Khastgir T, Gupta MP, et al. Clinical, haemodynamic and echocardiographic study in chronic cor pulmonale. JAPI 1989;37(6):373-6.

[8] Kellar CA, Shepard JW, Chun DS, et al. Pulmonary hypertension in chronic obstructive pulmonary disease. Multivariate analysis. Chest 1986;90(2):18592.

[9] Putnik M, Povazan D, Vindisjesic M. Electrocardiography and echocardiography in the diagnosis of chronic corpulmonale (Article in Serbo Croatian (Roman). Med Pregl 1998;51(11):528-31.

[10] Himelman RB, Struve SN, Brown JK, et al. Improved recognition of cor pulmonale in patients with severe chronic obstructive pulmonary disease. Am J Med 1988;84(5):891-8.

[11] MacNee W. Chronic bronchitis and emphysema. Chapter-23. In: Seaton A, Seaton D, Leitch G, eds. Crofton and Douglas' Respiratory diseases. $5^{\text {th }}$ edn. London: BlackWell Science Ltd., 2000: p. 616-95.

[12] Scott RC, Kaplan S, Fowler NO, et al. The electrocardiographic pattern of right ventricular hypertrophy in chronic cor pulmonale. Circulation 1955;11(6):927-36.
[13] Phillips RW, Providence RI. The electrocardiogram in Cor pulmonale secondary to pulmonary emphysema. A study of 18 cases proved by autopsy. American Heart Journal 1958;56(3):352-71.

[14] Padmavati S, Pathak SN. Chronic cor-pulmonale in Delhi: study of 127 cases. Circulation 1959;20:343-52.

[15] Caird FI, Wilcken DEL. The electrocardiogram in chronic bronchitis with generalized obstructive lung disease. Its relations to ventilator function. The American Journal of Cardiology 1962;10:5-13.

[16] Fowler NO, Daniels C, Scott R, et al. The electrocardiogram in cor pulmonale with and without emphysema. The American Journal of Cardiology 1965;16(4):500-5.

[17] Millard FJ. The electrocardiogram in chronic lung disease. British Heart Journal 1967;29(1):43-50.

[18] Silver HM, Calatayud JB. Evaluation of QRS criteria is patients with COPD. Chest 1971;59(2):153-9.

[19] Padmavathi S, Raizada V. Electrocardiogram in chronic cor pulmonale. British Heart Journal 1972;34(7):65867.

[20] Murphy ML, Hutcheson F. The electrocardiographic diagnosis of right ventricular hypertrophy in chronic obstructive pulmonary disease. Chest 1974;65(6):6227.

[21] McLaughlin VV, Rich S. Cor-pulmonale. Chapter-54. Heart Disease - a text book of cardiovascular medicine. Braunwald E. $6^{\text {th }}$ edn. Philadelphia: WB Saunders Company 2001:1936-54.

[22] Danchin N, Cornette A, Henriquez A, et al. Twodimensional echocardiographic assessment of the right ventricle in patients with chronic obstructive lung disease. Chest 1987;92(2):229-33.

[23] Louridas G, Patakas D, Stavropoulos C. Left ventricular function in patients with chronic obstructive pulmonary disease. Cardiology 1981;67(2):73-80.

[24] Vizza CD, Lynch JP, Ochoa LL, et al. Right and left ventricular dysfunction in patients with severe pulmonary disease. Chest 1998;113(3):576-83.

[25] Higham MA, Dawson D, Joshi J, et al. Utility of echocardiography in assessment of pulmonary hypertension secondary to COPD. Eur Respir J 2001;17(3):350-5. 